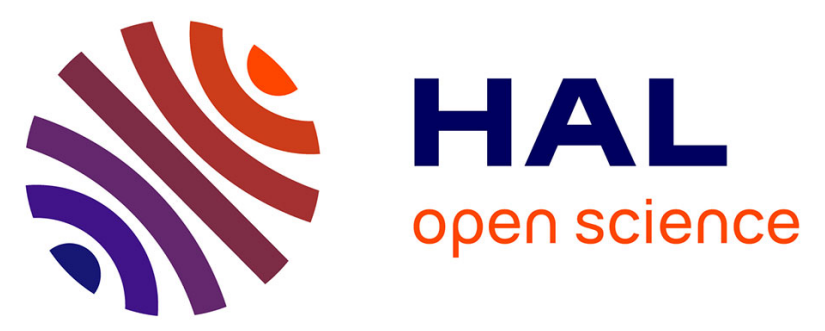

\title{
Pilot scale degradation of mono and multi volatile organic compounds by surface discharge plasma/TiO reactor Investigation of competition and synergism
}

Aymen Amine Assadi, Sivachandiran Loganathan, Phuong Nguyen Tri, Sara Gharib-Abou Ghaida, Abdelkrim Bouzaza, Anh Nguyen Tuan, Dominique Wolbert

\section{To cite this version:}

Aymen Amine Assadi, Sivachandiran Loganathan, Phuong Nguyen Tri, Sara Gharib-Abou Ghaida, Abdelkrim Bouzaza, et al.. Pilot scale degradation of mono and multi volatile organic compounds by surface discharge plasma/TiO reactor Investigation of competition and synergism. Journal of Hazardous Materials, 2018, 357, pp.305-313. 10.1016/j.jhazmat.2018.06.007 . hal-01834001

\section{HAL Id: hal-01834001 \\ https://hal-univ-rennes1.archives-ouvertes.fr/hal-01834001}

Submitted on 13 Jul 2018

HAL is a multi-disciplinary open access archive for the deposit and dissemination of scientific research documents, whether they are published or not. The documents may come from teaching and research institutions in France or abroad, or from public or private research centers.
L'archive ouverte pluridisciplinaire HAL, est destinée au dépôt et à la diffusion de documents scientifiques de niveau recherche, publiés ou non, émanant des établissements d'enseignement et de recherche français ou étrangers, des laboratoires publics ou privés. 
Pilot scale degradation of mono and multi volatile organic compounds by surface discharge plasma/ $\mathrm{TiO}_{2}$ reactor: investigation of competition and synergism

ASSADI Aymen Amine ${ }^{1, *}$, LOGANATHAN Sivachandiran ${ }^{2}$, TRI Phuong Nguyen ${ }^{3}$, GHARIB-ABOU GHAIDA Sara ${ }^{1}$, BOUZAZA Abdelkrim ${ }^{1}$, TUAN Anh Nguyen $^{4}$, WOLBERT Dominique ${ }^{1}$

${ }^{1}$ Laboratoire Sciences Chimiques de Rennes - équipe Chimie et Ingénierie des Procédés, UMR 6226 CNRS, ENSCR-11, allée de Beaulieu, CS 508307-35708 Rennes, France.

${ }^{2}$ Research Institute \& Chemistry Department, SRM University, Kattankulathur, Chennai - India ${ }^{3}$ Department of Chemistry, Pavillon J.-Armand-Bombardier, Montreal University, Montréal, QC ${ }^{4}$ Institute For Tropical Technology, 18 Hoang Quoc Viet Road, Cau Giay District, Hanoi, Vietnam

"Corresponding author. Tel.: +33 2 23238152; fax: +332 23238120.

E-mail address: Aymen.assadi@ensc-rennes.fr (A. ASSADI).

Graphical abstract
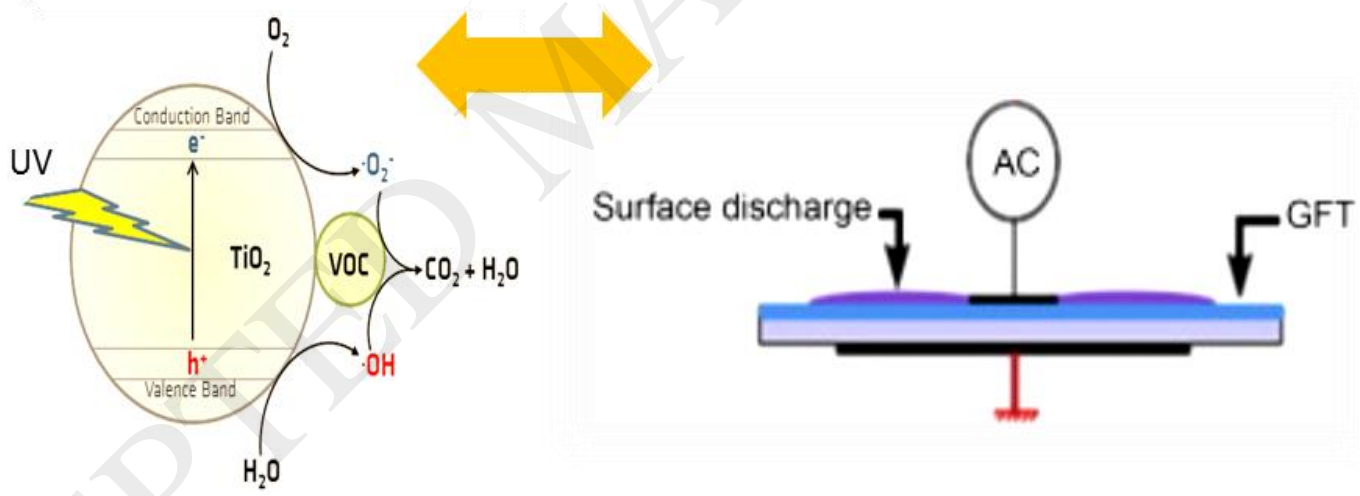

A nonthermal plasma surface discharge (NPSD) coupled with photocatalysis

\section{Highlights}

- Removal of pollutant in air mixture by photocatalysis and plasma is investigated

- Synergetic effect of combined system is explored.

- The by-products of each binary mixture were identified and evaluated.

- Monitoring of mineralization and ozone has been done at pilot scale. 
Abstract

This paper mainly deals with the isovaleraldehyde degradation with the help of a nonthermal plasma surface discharge (NPSD) coupled with photocatalysis. The efficiency of NPSD reactor, for gas treatment, was studied for different binary mixtures: (1) mixture of aldehydes (Isovaleraldehyde and Butyraldehyde) and (2) mixture of aldehyde and amine (Isovaleraldehyde and Trimethylamine). A planar continuous reactor is used to investigate the effect of addition of another pollutant on the performance of oxidation process.

A synergetic effect was observed by combining NPSD and photocatalysis for the degradation of mixture of pollutants. In addition, combined NPSD / photocatalysis has significantly enhanced the $\mathrm{CO}_{2}$ selectivity, as compared to NPSD alone. This is attributed to the formation of more reactive species due to the presence of $\mathrm{TiO}_{2}$ in the plasma discharge zone. Moreover, ozone and UV light on $\mathrm{TiO}_{2}$, produced by plasma, have activated the surface leading to enhanced mineralization. In addition, the byproducts of each binary mixture were identified and evaluated.

\section{Keywords}

Nonthermal plasma surface discharge, photocatalysis, VOC binary mixture, synergetic effect.

\section{Introduction}

Throughout the past century industrial, agricultural, and domestic activities have been responsible for the emission of many undesirable volatile organic compounds (VOCs) to the atmosphere. These compounds have drawn considerable attention in the last two decades as they were and still are major contributors to air pollution [1]. Therefore, the abatement of VOCs has become a major global challenge as its emission aggravated the problems of climate change and global warming. Consequently, different strategies are being developed to minimize, if not completely eliminated, the risks associated with VOCs emissions [2]. Indeed, the prevailing processes for emissions control such as incineration, absorption, adsorption, condensation, and biofiltration do not provide fully acceptable results [3].

As an outcome, advanced oxidation processes (AOPs) have emerged as suitable alternative technologies to effectively remove VOCs from gaseous effluents [4-7]. These AOPs are especially characterized by the in situ production of hydroxyl radical $\left({ }^{\circ} \mathrm{OH}\right)$ at room temperature [8]. Among the various AOPs, the photocatalytic and non-thermal plasma (NTP) 
catalytic processes have been widely investigated. Photocatalysis is based on the use of low energy UV photons to excite an electron from the conduction band to the valence band in a semiconductor catalyst (commonly $\mathrm{TiO}_{2}$ ) leading to the formation of electron-hole pairs [9]. The formed electrons and holes lead to the formation of very reactive hydroxyl radicals in the presence of moisture/water on photocatalytic surface or in the gas phase $[10,11]$. The $\mathrm{OH}^{\circ}$ produced on the catalyst surface effectively decomposes many toxic pollutants [11]. Nonetheless, photocatalytic oxidation has disadvantages like catalyst deactivation and slow process, which restricts its commercial application for depollution purposes.

In order to enhance the photodegradation performance, photocatalyst is usually combined with plasma discharge $[5, \mathbf{1 2}]$. Most commonly, for air depollution, electrical discharges are used to produce NTP-favorable for the removal of various pollutants (e.g., $\mathrm{NO}_{\mathrm{x}}$, odors, $\mathrm{SO}_{\mathrm{x}}$ and VOCs)under moderate conditions (i.e. room temperature and atmospheric pressure), which is intriguing towards industrialization of the process [13]. It is widely reported that the coupling of photocatalyst with NTP has shown considerable enhancement in the performance of the process [14-19].

In atmospheric NTP, highly energetic electrons and chemically reactive species (e.g., free radicals, excited atoms, ions, and molecules) are generated and implied into of both physical and chemical reactions. Nonthermal plasma treatment has a distinct non-equilibrium character, meaning that the gas temperature is near at room temperature, whilst the electrons are highly energetic with a typical mean temperature of 1-10 eV [20]. As a result, NTP can easily break most of the chemical bonds and triggers the thermodynamically unfavorable chemical reactions at room temperature. Therefore, the oxidation of VOCs using photocatalytic/NTP system, at room temperature, atmospheric pressure, and with molecular oxygen as the only oxidant, is promising [20]. The combined NPSD / photocatalysis system has been investigated previously, mostly for single pollutant removal, under UV irradiation $[\mathbf{8 , ~ 1 3 , ~ 1 8 ] . ~ T h e r e f o r e , ~ i t ~ c a n ~ b e ~}$ proposed that the integration of solid catalysts in plasma discharge area could have a great potential for generating a synergistic effect, improving their activity and resulting in a remarkable enhancement of pollutant oxidation and less by-products formation.

In this work, a pilot scale planar dielectric barrier discharges (DBD) reactor has been developed for the plasma/photocatalytic oxidation of two binary mixtures of pollutants. The effect of photocatalysts on the oxidative removal of pollutants has been evaluated. Moreover, the mutual effect between pollutants and the influence of concentration on oxidation pathway have also been studied. Indeed, the synergistic effect between NTP and photocatalyst for various pollutants is explored in pilot scale process. 


\section{Materials and methods}

\subsection{Chemicals and analysis}

Chemicals are purchased from Sigma-Aldrich (USA) at various purity grades: Isovaleraldehyde (Isoval) ( $\geq 98 \%$ ), Trimethylamine (TMA) in water (50\%) and Butyraldehyde (Buty) ( $\geq 99 \%$ ). All chemicals are used as received without any further purification.

The gas products are analyzed by a dual-channel gas chromatography Fisons GC9000 equipped with a flame ionization detector (FID). The separations of Isoval, Buty and by-products are performed by a Chrompact FFAP-CB column and nitrogen gas is used as the mobile phase. The temperature of oven, the injector and the detector are, 100, 120 and $200{ }^{\circ} \mathrm{C}$, respectively. The details of the analysis system were given elsewhere $[7,13]$. The by-products produced by the combined system, during the degradation of mixture of VOCs, were identified using a Gas chromatography-mass spectrometry (GC-MS, Perkin Elmer Clarus 500). The GC was equipped with Chrompac TM capillary column FFAP-CB $(60 \mathrm{~m} \times 0.32 \mathrm{~mm} \times 1 \mu \mathrm{m})$. This column was connected to Mass Spectrometer (MS) devoted to compounds identification. Due to very low concentrations, the sample was focused on a multi-bed cartridge (Carbopack B). After heating, it was refocused on a trap filled with Carbopack B at $173 \mathrm{~K}$, so-called Cooled Injection System (CIS). The splitless sample Injection method was opted to inject the refocused sample to GC-MS.

\subsection{Catalyst synthesis}

The photocatalytic material, which is provided by Ahlstrom [21], consists of a mixture of $\mathrm{TiO}_{2}$ and $\mathrm{SiO}_{2}$ deposited on Glass Fiber Tissue (GFT) with $2 \mathrm{~mm}$ thickness. Indeed, $13 \mathrm{~g} / \mathrm{m}^{2}$ of colloidal silica ensure the fixation of $13 \mathrm{~g} / \mathrm{m}^{2}$ of titanium dioxide nanoparticles (PC500 Millennium). As prepared colloidal $\mathrm{TiO}_{2} / \mathrm{SiO}_{2}$ nanoparticle is deposited on GFT by wet impregnation method in pure water. The total specific surface area of the $\mathrm{TiO}_{2} / \mathrm{SiO}_{2} / \mathrm{GFT}$ is $20.6 \mathrm{~m}^{2} \cdot \mathrm{g}^{-1}[\mathbf{2 1}]$.

\subsection{Gas stream preparation}

As shown in Fig. 1, the TMA, Buty and Isoval were directly injected in liquid state into dry air flow, supplied by the compressed air system, using two syringe pumps (Fig.1). The heating 
tapes were wrapped on stainless steel pipe at the injection zones to ensure good evaporation of each pollutant. The static mixer, placed upstream the reactor, was used for the homogenization of the mixture. The air flow was controlled by a mass flow controller (MFC, Bronkhorst) calibrated with normal cubic meter per hour on the range $0-10 \mathrm{~m}^{3} \cdot \mathrm{h}^{-1}$ (Fig. 1).

\subsection{Non Thermal plasma/photocatalytic reactor}

As can be seen in Fig. 2, the rectangular planar glass reactor consists of $1000 \mathrm{~mm}$ length and $135 \mathrm{~mm}$ width. Inside the glass reactor, a rectangular shape stainless steel plates with $2 \mathrm{~mm}$ thickness, were inserted and used as high voltage electrodes. The copper sheet, with $1 \mathrm{~mm}$ thickness, wrapped around the planar reactor was employed as a ground electrode. The discharge length was fixed at $800 \mathrm{~mm}$.In planar reactor, $\mathrm{TiO}_{2} / \mathrm{SiO}_{2} / \mathrm{GFT}$ is used as a photocatalyst and eight lamps (Philips PL-S 9 W / 10 / 4 P) were used as a UV source. The details of the high voltage power source and discharge characteristics of the quartz reactor are reported elsewhere [13, 22-24]. Briefly, in planar DBD reactor, plasma surface discharge was ignited using an AC high voltage power supply with a fixed voltage of $20 \mathrm{kV}$ (peak-to-peak) and $50 \mathrm{~Hz}$ frequency. The applied and discharge voltage were measured by a four-channel digital oscilloscope (Lecroy).

To evaluate the performance of the NTP/photocatalyst combined system, the specific energy density (SED), the removal efficiency, and the elimination capacity are calculated using the following equations:

$\operatorname{SED}(\mathrm{J} / \mathrm{L})=\frac{P(W)}{1000 \times \frac{Q\left(m^{3} / h\right)}{3600}}$

Where SED is the specific energy density $(\mathrm{J} / \mathrm{L})$ and $\mathrm{Q}$ is the flowrate $\left(\mathrm{m}^{3} / \mathrm{h}\right)$.

Removal Efficiency (RE), is calculated by the following equation:

$\mathrm{RE}(\%)=\frac{\mathrm{C}_{\text {in }}-\mathrm{C}_{\text {out }}}{\mathrm{C}_{\text {in }}} \times 100$

Elimination Capacity (EC), is determined using the following equation:

$\mathrm{EC}(\mathrm{mg} / \mathrm{h})=\left(C_{\text {in }}-C_{\text {out }}\right) \times \mathrm{Q}_{\text {air }}$

Where $\mathrm{C}_{\mathrm{in}}$ and $\mathrm{C}_{\text {out }}$ are the inlet and outlet pollutant concentrations (mg.m $\mathrm{m}^{-3}$ ), respectively.

The synergistic effect $(\mathrm{F})$ of plasma surface discharge and photocatalysis for VOC removal is defined as follows:

$\mathrm{F}(\%)=\langle\mathrm{RE}(\%)\rangle_{\text {combinedsystem }}-\left(\langle\mathrm{RE}(\%)\rangle_{\text {Plasma }}+\langle\mathrm{RE}(\%)\rangle_{\text {Photocatalysis }}\right)$ 
Where $\langle\mathrm{RE}(\%)\rangle_{\text {combinedsystem }}$ is VOC's removal efficiency of photo and plasma catalysis; $\langle\text { RE (\%) }\rangle_{\text {Plasma }}$ is VOC's removal efficiency of plasma catalysis alone (\%); $\langle\operatorname{RE}(\%)\rangle_{\text {Photocatalysis }}$ is VOC's removal efficiency of photocatalysis alone (\%).

The selectivity of $\mathrm{CO}$ and $\mathrm{CO}_{2}$ is calculated as follows:

$\operatorname{SCO}_{\mathrm{X}}(\%)=\left[\mathrm{CO}_{\mathrm{X}}\right] /\left(\sum\left[\mathrm{nC}_{\mathrm{i}}, \mathrm{COV} \times\left(\mathrm{C}_{\mathrm{in}, \mathrm{i}}-\mathrm{C}_{\text {out }, \mathrm{i}}\right)\right]\right.$

Where $\mathrm{n}$ is number of carbon atoms in the VOCs, COx is the total concentration of $\mathrm{CO}$ and $\mathrm{CO}_{2}$.

\section{Results and Discussion}

This study is aimed at the removal of different types of VOCs in mixture. However, in order to understand the oxidation behavior of VOCs in a mixture, initial experiments were carried out with single VOC/air mixture in $\mathrm{TiO}_{2} / \mathrm{SiO}_{2} /$ GFT packed planar reactor with an external UV light and the results are discussed in the following section.

\subsection{Photocatalytic removal}

\subsubsection{Single VOC removal}

The photocatalytic single VOC removal efficiency of the reactor has been studied for various inlet concentrations. For all model VOCs, the inlet concentrations were varied from 0.6 to 2.45 $\mathrm{mmol} . \mathrm{m}^{-3}$. The elimination capacity of the photocatalytic process, for three different VOCs with various inlet concentrations, is shown in Fig. 3.

For all pollutants, the degradation rate increases with increasing the inlet concentration. It is observed that with low inlet concentration, the degradation rate obeys first-order kinetics, i.e. the degradation rate is proportional to the inlet concentration. In this case, the limiting steps are the adsorption of pollutants onto the catalyst surface and desorption of the product to the gas phase. It can be suggested that initially not all the photoactive sites are occupied. Indeed an increase in the bulk concentration increases the surface coverage thus increases the VOC degradation efficiency. It is observed that at higher inlet concentration, more than $2 \mathrm{mmol} . \mathrm{m}^{-3}$, the elimination capacity reaches steady state. This can be explained by the fact that, under higher inlet concentration, the photoactive sites are saturated in the first few minutes, thereafter increase in the inlet concentration does not show any significant changes in the pollutant 
elimination capacity. The similar behavior was also observed for Isoval and TMA, these results are in line with those reported previously [24].

It is worth to mention that the oxidation kinetic of TMA is much lower than that of other aldehydes. This fact can be explained by the following hypotheses: i) the reactive adsorption of aldehydes on $\mathrm{TiO}_{2}$ surface, and ii) the influence of the byproducts formation. It is widely reported that the aldehydes and ketones are strongly adsorbed on $\mathrm{TiO}_{2}$ surface, even under dark conditions, and lead to aldol reaction [18]. In turn, these produced species by photocatalytic process will effectively react with the newly formed species, leading to $\mathrm{CO}_{2}$ formation in the gas phase. It can be suggested that the degradation pathway of TMA is more complicated than aldehydes. Consequently, the degradation of TMA probably produces more by-products which could accumulate in the bulk and on the surface. These by-products, containing mainly nitrogenous and carbonaceous derivatives, could competitively adsorb with initial molecules on the same active sites $[\mathbf{1 0}, \mathbf{1 1}]$. Therefore, it can be proposed that the competitive adsorption and by-products formation have significantly affected the TMA removal efficiency as compared to Isoval and Buty.

\subsubsection{Multi VOCs removal}

Fig. 4 shows the elimination capacity of the mixture of Isoval and Buty with various inlet concentrations like: 25,50 , and $100 \%$ of each pollutant.

As can be seen in Fig. 4 (a) and (b), it is observed that the elimination capacity of the individual pollutant is enhanced when mixed together. Interestingly, from monocompound to multicomponent systems, the EC has increased from 92 to $125 \mathrm{mg} / \mathrm{h}$ for Isoval when the inlet concentration is about $1.11 \mathrm{mmol} / \mathrm{m}^{3}$. It is evidenced that Isoval highly oxidized in multicomponent system than when it was in monocomponent system. This trend can be due to the chemical affinity of pollutants towards the active sites. A better affinity of Isoval allows it to occupy more active sites and then to be more degraded. As shown in Figure 4 a \& b, Buty conversion decreased, in the order of VOC mixture with $50 \%$ Buty $+50 \%$ Isoval $>$ VOC mixture with $75 \%$ Buty $+25 \%$ Isoval. For two levels of inlet concentration, Buty conversion in multicomponent system is higher than single component at the same conditions, indicating that there is a synergetic effect of multicomponent system. This effect will be confirmed later by the identification of the byproducts formed in multicomponent system.

\subsection{Plasma/photocatalytic process}


Here we summarize the results of isovaleraldehyde and butyraldehyde treatment with plasma alone and plasma/ $/ \mathrm{TiO}_{2}$ catalytic reactor in multicomponent and monocomponent systems. Moreover, to evaluate the mutual effects of mixture removal efficiency, the Trimethylamine (TMA), another VOC of amine group, has also been mixed with Isoval and tested under the same conditions as like Buty/Isoval mixture.

\subsubsection{Photo/plasma catalytic removal of binary mixture of $50 \%$ Buty $+50 \%$ Isoval}

Fig. 5 shows the removal efficiencies of Isoval and Buty in single and multi VOC systems using NPSD plasma, photocatalysis and a combined process. It is noticed that the mixing of pollutants has decreased the removal efficiency as compared to the treatment of a single component. Mingling of Isoval and Buty leads to reduce their maximum removal efficiencies by 30 and $20 \%$, respectively.

Therefore, it can be suggested that the treating of mixed VOCs could produce more byproducts, thus the consuming electrons or radicals produced by the silent discharge.

In one hand, as reported in Fig. 4, the photocatalytic treatment of mixture of pollutant significantly improves the removal efficiency. On the other hand, the removal efficiency of multicomponent system has been decreased by $50 \%$ in NPSD on $\mathrm{TiO}_{2} / \mathrm{SiO}_{2} / \mathrm{GFT}$ as compared to a single VOC. This can be explained by the fact that the competition occurs between the pollutants with the active species such $\mathrm{O}^{\circ}$ and $\mathrm{HO}^{\circ}$.

It is interesting to note that a synergetic effect is observed, irrespective of the mixture, when NPSD and photocatalyst is combined,

At lab and in pilot scales, previous studies have shown that combining plasma with photocatalysis has induced a synergetic effect on the oxidation efficiency of VOC in monocomponent system with flow rate varied from 1 to $500 \mathrm{~m}^{3} / \mathrm{h}[\mathbf{7 , 1 3}$. Indeed, in this study, the synergetic effect is observed for multicomponent system. Moreover, the factor of synergetic effect $(\mathrm{F} \%)$ for each VOC in mixture is about 8-10\% under the same conditions when plasma and photocatalysis are performed individually. This result is in good agreement with the report in the literature [14]. And also, in accordance with the observations of Piotrowska et al. It is reported that the elimination of n-butyl acetate was better in a mixture of aromatics and alcohols [6].

The synergetic effect of NPSD/photocatalytic process can be explained by the following hypotheses: 
- Action of free radicals $\left(\mathrm{N}^{*}, \mathrm{O}^{*}, \mathrm{H}^{*}, \mathrm{OH}^{*}\right)$ produced by the dissociation of molecules like $\mathrm{N}_{2}$, $\mathrm{O}_{2}, \mathrm{H}_{2} \mathrm{O}$. These actives species can interact directly with Buty and Isoval molecules in multicomponent system [25-27].

- Regeneration of $\mathrm{TiO}_{2}$ surface by DBD surface discharge $[\mathbf{5 , 9}]$ due to ionic winds. This would lead to the more active sites available for VOCs adsorption and subsequent enhanced conversion.

- Decomposition of ozone on the surface of $\mathrm{TiO}_{2}$ which gives more active species such as $\mathrm{O}^{*}$ for Buty and Isoval oxidation $[\mathbf{1 2}, \mathbf{2 8}]$.

\subsubsection{Removal of Isoval and TMA in single component and in binary mixture (50\% TMA+ 50\% Isoval)}

In this section, in order to understand the influence of TMA addition on Isoval removal process and vice-versa, the binary mixture of $50 \% \mathrm{TMA}+50 \%$ Isoval has been prepared and treated using plasma, photocatalytic and combined process. The concentration of TMA and Isoval have been varied between 0.5 to $1.7 \mathrm{mmol} / \mathrm{Nm}^{3}$. Fig. 6 shows the removal efficiencies (\%) of Isoval and TMA in mono and multicomponent systems. Interestingly, the removal efficiencies of TMA decrease with increasing the Isoval concentration. This observation is contrary to the result observed with binary mixture of $50 \%$ Isoval+ $50 \%$ Buty. This can be attributed the chemical bond strength and molecular stability of the TMA [7]. As can be seen in Fig. 6, when Isoval is mixed with TMA the removal efficiency decreased from 30 to $13 \%$ as compared to single component.

As seen from the data presented in previous publication [7] and in the present study, the elimination capacity of any pollutant with combined system was higher than the sum of elimination capacities with plasma NPSD and photocatalysis performed separately.

As reported in Fig. 6, synergistic effect is observed in combined system. Indeed, factor of synergistic effect (F\%) is about $10 \%$ for Isoval and TMA of single and binary mixture.

\section{End products analysis}

It is observed that the $\mathrm{CO}$ formation in plasma and photocatalytic combined system, irrespective of the inlet concentration, is negligible. Similar results have also been reported for the photocatalytic removal of cyclohexane [13], trichloroethylene [11], and formaldehyde [28]. 


\section{1. $\mathrm{CO}_{2}$ selectivity}

The $\mathrm{CO}_{2}$ selectivity of each tested pollutant was shown in figure 7 . It is widely reported that the photocatalytic process was a series of successive reactions; the competition towards the active sites of the catalyst becomes more important.

The $\mathrm{CO}_{2}$ selectivity of Isoval (with DBD plasma alone) was about $43 \%$ and this value was about $62 \%$ for the combined DBD/photo catalysis processes. Consequently, this behavior is due to the photocatalytic activity of $\mathrm{TiO}_{2}$ in the presence of UV radiation. In fact, when the two processes are combined, carbon dioxide selectivity was improved as compared to DBD plasma alone, irrespective of the pollutant tested $[\mathbf{2 6}, \mathbf{2 8}]$

Using DBD plasma alone, the low values of overall $\mathrm{CO}_{2}$ selectivity were explained by the fact that the quantities of generated reactive species become insufficient, leading to a limited chemical reaction. These results are in line with those in the literature related to formaldehyde [19] and isovaleraldehyde removal [28].

On the other hand, combined DBD plasma/photocatalysis significantly enhances the $\mathrm{CO}_{2}$ selectivity, as compared to DBD plasma alone. This is attributed to the formation of more reactive species due to the presence of $\mathrm{TiO}_{2}$ in the plasma discharge zone. Moreover, UV radiation is able to activate ozone on the surface of $\mathrm{TiO}_{2}$ to improve mineralization. Consequently, possible pathways for pollutant removal in combined DBD plasma/photocatalysis mainly include gas-phase radical attacks due to various other species such as high-energy electrons, excited molecules or radicals.

In fact, from single component to multicomponent system, an inhibition effect for the collectivity of three processes tested is observed. On the other hand, the mixture (TMA and Isoval) seems to be more affected in multicomponent systems. This behavior may be attributed to the mineralization of TMA which is less than that for Buty due to the less conversion of TMA to intermediate species compared to Buty. Thus, the Buty intermediates have more probability to be attacked by electrons and active species.

\subsection{Ozone formation}

Ozone is well known, as an unwanted and inevitable, by-product during plasma oxidation. Moreover, it plays an important role during VOC oxidation. The atomic oxygen is formed by in-situ decomposition of ozone and reacts with the pollutants. 
The residual ozone concentration in the reactor exhaust for each process (plasma alone and the combined process) is reported in Figure 8. It is can be seen that, from mono to multicomponent system, with plasma/ $\mathrm{TiO}_{2}$ reactor, ozone concentration is decreased as compared to plasma alone. This can be explained by the fact that $\mathrm{TiO}_{2}$ surface is activated by $\mathrm{UV}$ radiation, which can reduce the formation of ozone or favor its destruction [17]. On the other hand, results with multicomponent systems illustrate that the active species $\left(\mathrm{O}^{\bullet}\right)$ generated by plasma, are able to oxidize by-products and to react with oxygen molecules to form ozone [8].

\section{By-products formation}

\subsection{Isoval and Buty in multicomponent systems}

The formation of by-products in plasma/ $\mathrm{TiO}_{2}$ reactor, for the selected VOCs, was investigated. Figure 9 shows the by-products detected when the treated gas concentration was around 1 $\mathrm{mmol} / \mathrm{m}^{3}$. As can be seen in Fig. 9, about seven by-products have been formed when the plasma and the photocatalysis is combined which is in line with the finding of Gharib et al., [29]. When only Buty is treated by plasma/photocatalysis system along with non-treated Buty, the following intermediates have been identified: acetone (1), ethyl acetate (2), acetic acid (4), propionic acid (5) and butyric acid (6) are detected. It is worth mentioning that the similar kind of intermediates, as in plasma/ $\mathrm{TiO}_{2}$ reactor, have also been detected when plasma was used alone. Interestingly, at the reactor downstream, ethanol (3), isobutyric acid (7) and residual Isoval have been identified when Isoval is added to the mixture.

\subsection{Isoval and TMA multicomponent system}

In our previous study, a special attention was devoted to the analysis of reaction products during TMA degradation in a single component system [29] and the following by-products are identified: (Dimethylamino) acetonitrile, N, N-Dimethyl formamide, nitromethane, acetone, acetic acid, methanol, and ethanol [29]. Moreover, the oxidation of TMA leads to the formation of NOx. On the contrary, as reported in Fig. 10, when the TMA is incorporated with Isoval, the detected by-products are: acetone, isobutyric acid, methanol, acetic acid and $\mathrm{CO}_{2}$. Importantly, carbon-nitrogen compounds are not identified as noticed in single component system. This can be attributed to the recombination of by-products (TMA or/and Isoval). 


\section{Conclusion}

In this study, removal of volatile organic compounds, in single component and multicomponent systems by surface discharge plasma/ $/ \mathrm{TiO}_{2}$ combination, were systematically investigated in a continuous flow reactor. Aldehydes (Isoval and Buty) and trimethylamine could be effectively removed by combined systems.

The main findings can be summarized as follows:

(1) The degradation of the two compounds in the mixture was inhibited in comparison to the degradation of the pure compounds. The photocatalytic oxidation step of the two aldehydes was found to be competitive. The highly -volatile compound (Isoval) was less adsorbed on the catalyst surface however more conversion is observed, probably due to the influence of less by-products formation.

(2) The nature of all by-products from VOCs mixture decomposition were successfully identified using GC-MS.

(3) For each operating mixture of pollutants, we have unambiguously shown that there was a synergetic effect for the pollutants oxidation and the combination of plasma and $\mathrm{TiO}_{2}$ shown promising results for the removal of low concentrated volatile organic compounds from air.

\section{Acknowledgements}

The authors would like to thank the Ecole Nationale Supérieure de Chimie de Rennes (ENSCR France) for the financial support of this work. 


\section{References}

[1] H. T. Quoc An, T. Pham Huu, T. Le Van, J. M. Cormier, A. Khacef, "Application of atmospheric non-thermal plasma-catalysis hybrid system for air pollution control: Toluene removal," Catal. Today, vol. 176 (2011) 474-477.

[2] ADEME: http://www2.ademe.fr/servlet/KBaseShow?sort=-1\&cid=96\&m=3\&catid=15979.

[3]G.R. Parmar, N.N. Rao, Emerging Control Technologies for Volatile Organic Compounds. Crit. Rev. Env. Sci. Technol. 39 (2009) 41-78.

[4] Van Durme, J.; Dewulf, J.; Leys, C.; Van Langenhove, H., Combining non-thermal plasma with heterogeneous catalysis in waste gas treatment: A review, Applied Catalysis B: Environmental, 78 (2008) 324-333.

[5] G. Maxime, A. A. Amine, B. Abdelkrim, W. Dominique, Removal of gas-phase ammonia and hydrogen sulfide using photocatalysis, nonthermal plasma, and combined plasma and photocatalysis at pilot scale, Environmental Science and Pollution Research 21 (22) 1312713137.

[6] A. Musialik-Piotrowska, K. Syczewska, Catalytic oxidation of trichloroethylene in twocomponent mixtures with selected volatile organic compounds, Catalysis Today, 73 3-4 (2002) 333-342.

[7] A.A. Assadi, A. Bouzaza, C. Vallet, D. Wolbert, Use of DBD plasma, photocatalysis, and combined DBD plasma/photocatalysis in a continuous annular reactor for isovaleraldehyde elimination-synergetic effect and byproducts identification, Chem. Eng. J. 254 (2014) 124132.

[8] I. Aouadi, J.-M.Tatibouët, L. Bergaoui, MnOx/TiO2 Catalysts for VOCs Abatement by Coupling Non-thermal Plasma and Photocatalysis, Plasma Chem Plasma Process 36 (2016)1485-1499. 
[9] Erik C. Neyts, Plasma-Surface Interactions in Plasma Catalysis, Plasma Chem Plasma Process 36 (2016) 185-212.

[10] Y. Boyjoo, H. Sun, J. Liu, V. K. P., Sh. Wang, A review on photocatalysis for air treatment: From catalyst development to reactor design, Chemical Engineering Journal 310 (2017) 537559

[11] L. Zhong, F.Haghighat, Ch.Lee, N. Lakdawala, Performance of ultraviolet photocatalytic oxidation for indoor air applications: Systematic experimental evaluation, Journal of Hazardous Materials, 261(2013) 130-138.

[12] C. Klett, X. Duten, S. Tieng, S. Touchard, P. Jestin, K. Hassouni, A. Vega-González, Acetaldehyde removal using an atmospheric non-thermal plasma combined with a packed bed: Role of the adsorption process, Journal of Hazardous Materials, 279 (2014) 356-364.

[13 ] A. A. Assadi, A. Bouzaza, I. Soutrel, P. Petit, K. Medimagh, D. Wolbert, A study of pollution removal in exhaust gases from animal quartering centers by combining photocatalysis with surface discharge plasma: from pilot to industrial scale, Chemical Engineering and Processing: Process Intensification 111, ( 2017) 1-6

[14] J. Karuppiah, E. Linga Reddy, P. Manoj Kumar Reddy, B. Ramaraju, R. Karvembu, Ch. Subrahmanyam, Abatement of mixture of volatile organic compounds (VOCs) in a catalytic non-thermal plasma reactor, Journal of Hazardous Materials 237-238 (2012) 283-289.

[15] C. Subrahmanyam, M. Magureanu, D. Laub, A. Renken, L. Kiwi-Minsker, Nonthermal plasma abatement of trichloroethylene enhanced by photocatalysis, J. Phys. Chem. C. 111 (2007) 4315-4318.

[16] A.A. Assadi, A Bouzaza, D Wolbert, P Petit, Isovaleraldehyde elimination by $\mathrm{UV} / \mathrm{TiO}_{2}$ photocatalysis: comparative study of the process at different reactors configurations and scales, Environmental Science and Pollution Research 21 (19) 11178-11188 
[17] L. Sivachandiran, F. Thevenet, P. Gravejat, A. Rousseau, Isopropanol saturated $\mathrm{TiO}_{2}$ surface regeneration by non-thermal plasma: Influence of air relative humidity, Chem. Eng. J. 214 (2013) 17-26.

[18] L. Sivachandiran, F. Thevenet, A. Rousseau, Non-Thermal Plasma Assisted Regeneration of Acetone Adsorbed $\mathrm{TiO}_{2}$ Surface, Plasma Chem. Plasma Process. 33 (2013) 855-871.

[19] X. Zhu, X. Gao, R. Qin, Y. Zeng, R. Qu, C. Zheng, X. Tu, Plasma-catalytic removal of formaldehyde over $\mathrm{Cu}-\mathrm{Ce}$ catalysts in a dielectric barrier discharge reactor, Appl. Catal. B 170 (2015) 293-300.

[20] W. Wang, X. Fan, T. Zhu, H. Wang, D. Ye, X. Hong, Removal of gas phase dimethylamine and N,N-dimethylformamide using non-thermal plasma, Chemical Engineering Journal, 299, (2016), 184-191.

[21] Ahlstrom Patent EP 1069950, 2000. AU 735798 US 09/467, 650; JP 2000- 542104.

[22] A. A. Assadi, J. Palau, , A. Bouzaza, J. Penya-Roja, V.Martinez-Soria, D. Wolbert, Abatement of 3-methylbutanal and trimethylamine with combined plasma and photocatalysis in a continuous planar reactor, Journal of Photochemistry and Photobiology A: Chemistry 282 (2014) 1-8.

[23] G. Costa, A. A. Assadi, S. Gharib-Abou, A. Bouzaza, D. Wolbert, Study of butyraldehyde degradation and by-products formation by using a surface plasma discharge in pilot scale: Process modeling and simulation of relative humidity effect., Chemical Engineering Journal, 307 (2017) 785-792.

[24] A. A. Assadi, J. Palau, A. Bouzaza, D.Wolbert, A continuous air reactor for photocatalytic degradation of Isovaleraldehyde: Effect of different operating parameters and Chemical degradation pathway, Chemical Engineering Research and Design 91, (2013), 1307-1316.

[25] A. Fridman, A. Chirokov; A. Gutsol, Non-thermal atmospheric pressure discharges. Journal of Physics D: Applied Physics, 38 (2005) R1-R24. 
[26] J. Chen, Zh.Xie, J. Tang, J.Zhou, X. Lu, H. Zhao, Oxidation of toluene by dielectric barrier discharge with photo-catalytic electrode, Chemical Engineering Journal 284 (2016) 166-173.

[27] K. Kim, J. Kim, Y.Son, S.Chung, J. Kim, Advanced oxidation of aromatic VOCs using a pilot system with electron beam-catalyst coupling, Radiation Physics and Chemistry, 81(2012) 561-565.

[28] J. Palau, A.A. Assadi, J.M. Penya-roja, A. Bouzaza, D. Wolbert, V. Martínez-Soria, Isovaleraldehyde degradation using UV photocatalytic and dielectric barrier discharge reactors, and their combinations, Journal of Photochemistry and Photobiology A: Chemistry, 299( 2015) 110-117.

[29] S. Gharib-Abou Ghaida, A. A. Assadi G. Costa, A. Bouzaza, D. Wolbert, Association of surface dielectric barrier discharge and photocatalysis in continuous reactor at pilot scale: Butyraldehyde oxidation, by-products identification and ozone valorization, Chemical Engineering Journal, 292 (2016) 276-283 


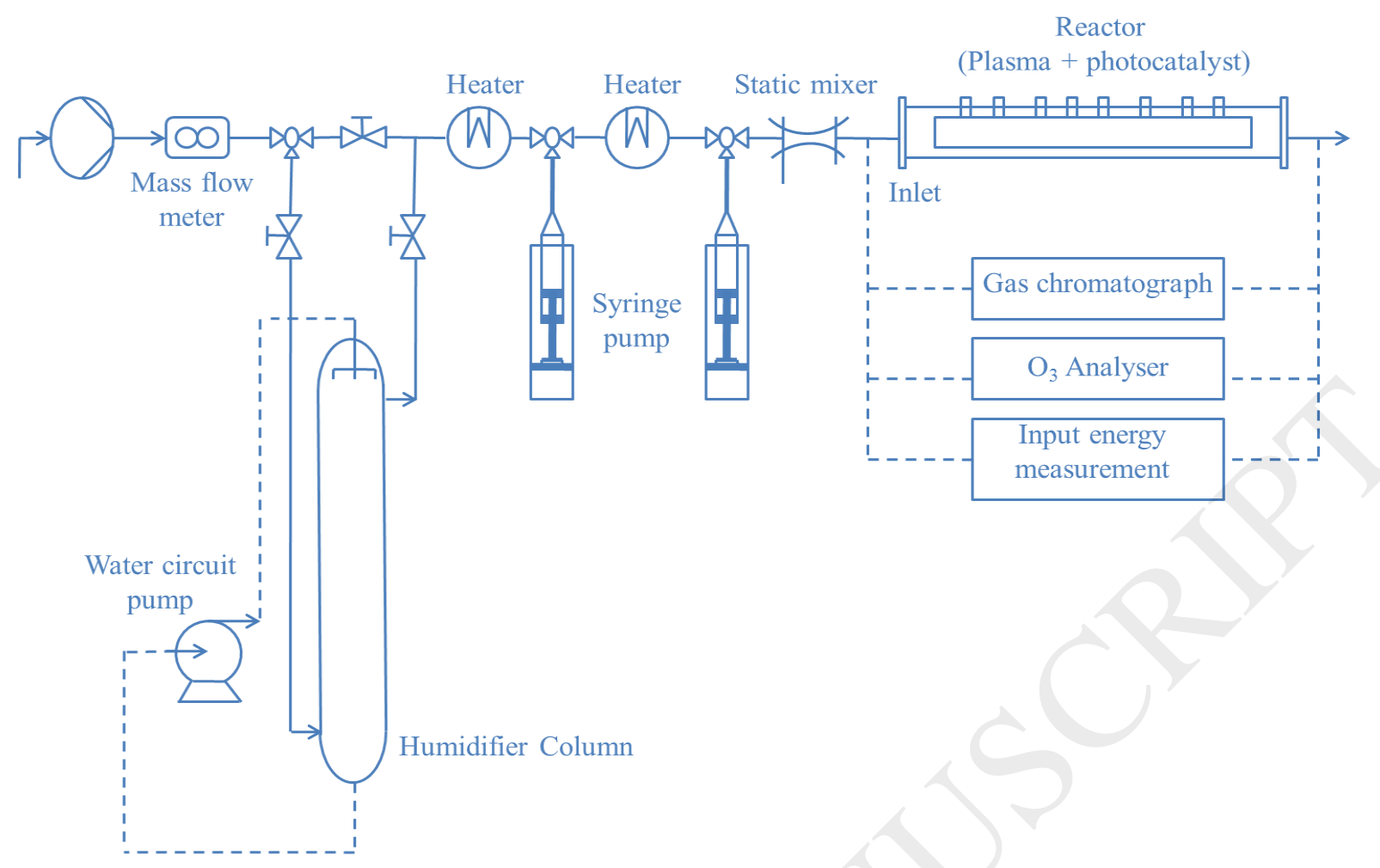

Fig 1: Experimental set-up.

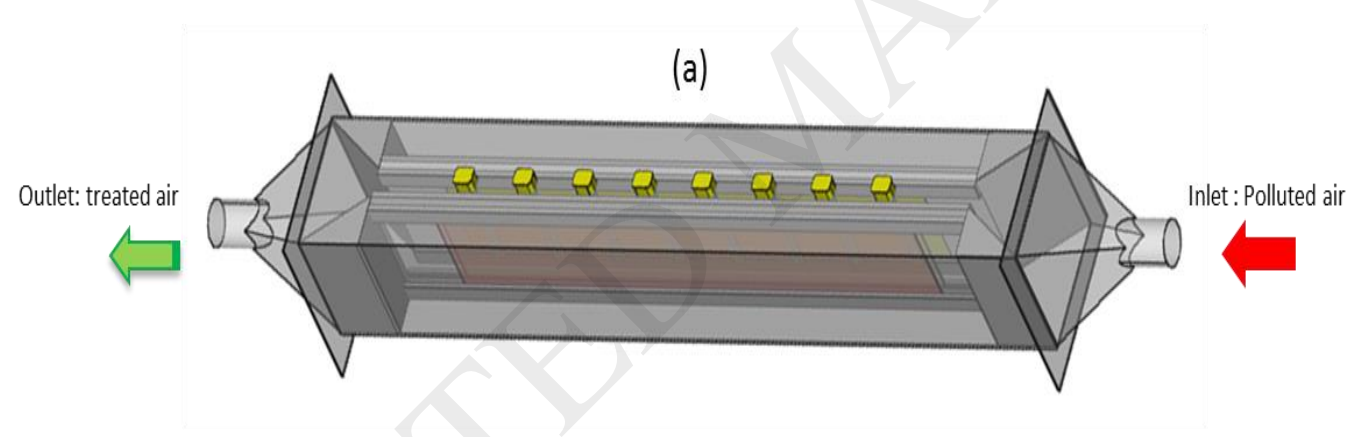

(b)

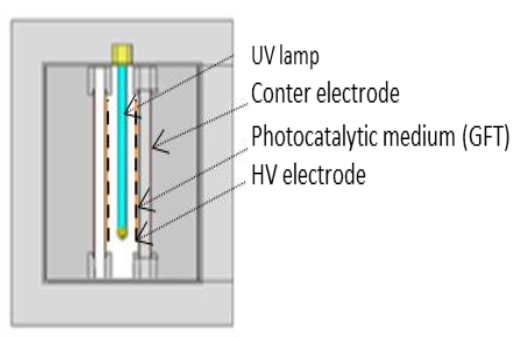

Fig. 2: Schema (a) and cross sectional drawing (b) of the planar reactor. 


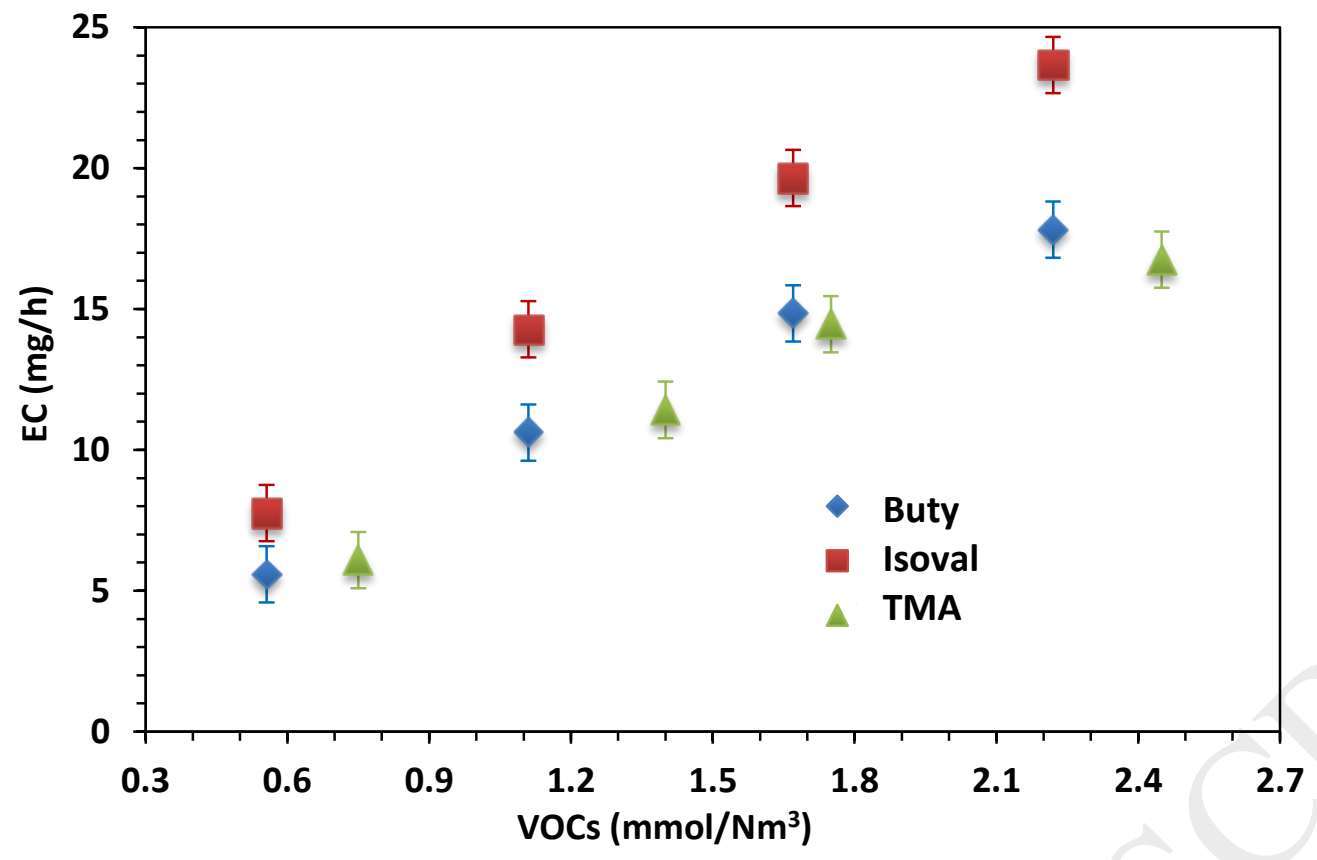

Figure 3: Evolution of the individual photocatalytic elimination capacity of TMA, Isoval and Buty with various inlet concentrations (Planar reactor, $\mathrm{T}=20^{\circ} \mathrm{C}, \mathrm{UV}$ intensity $=20 \mathrm{~W} \cdot \mathrm{m}^{-2}$ ). 

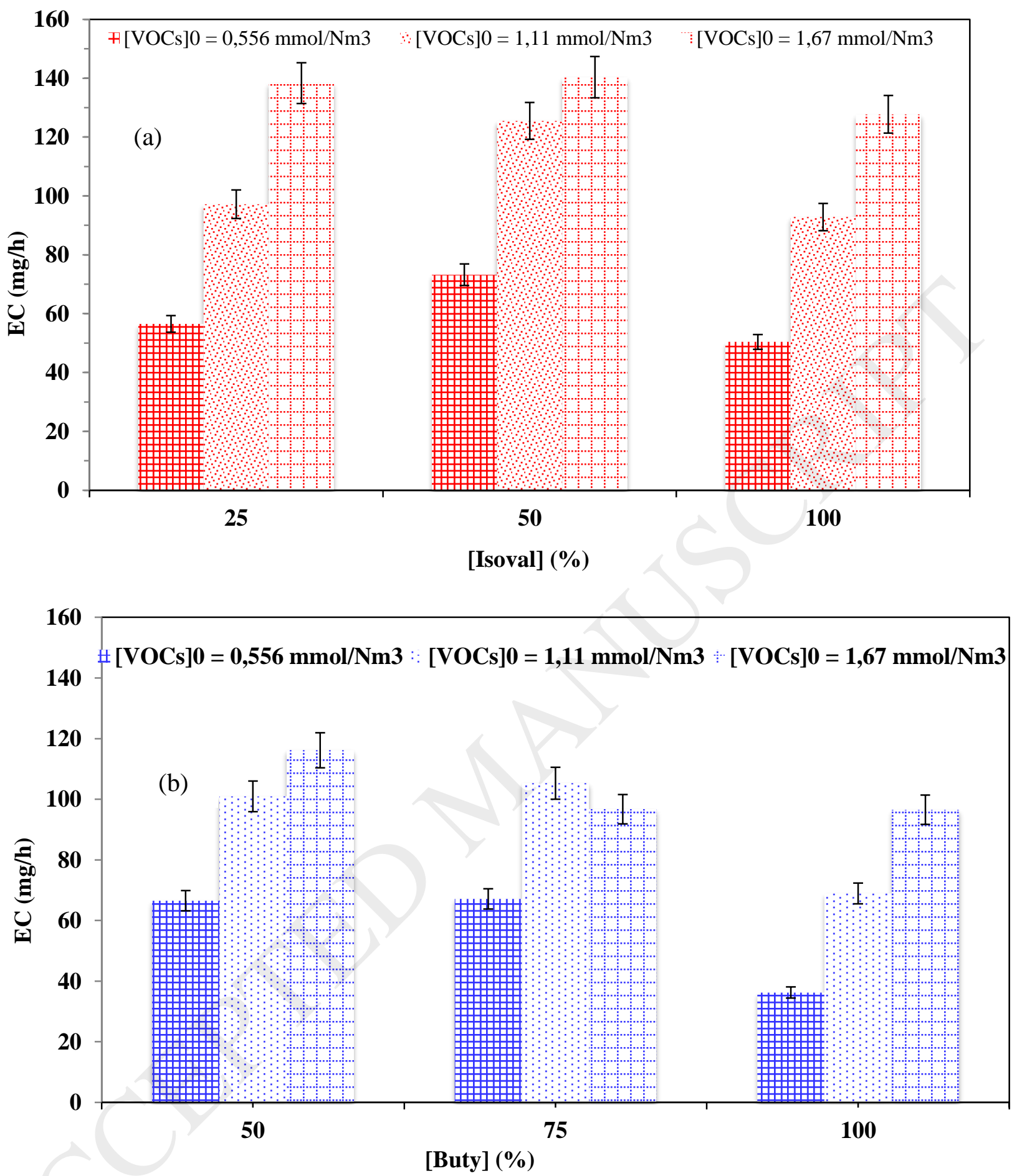

Figure 4: Evolution of the elimination capacity of: a) Isoval and b) Buty introduced at different concentrations in binary mixtures (Planar reactor, UV intensity $=20 \mathrm{~W} \cdot \mathrm{m}^{-2}$ ). 


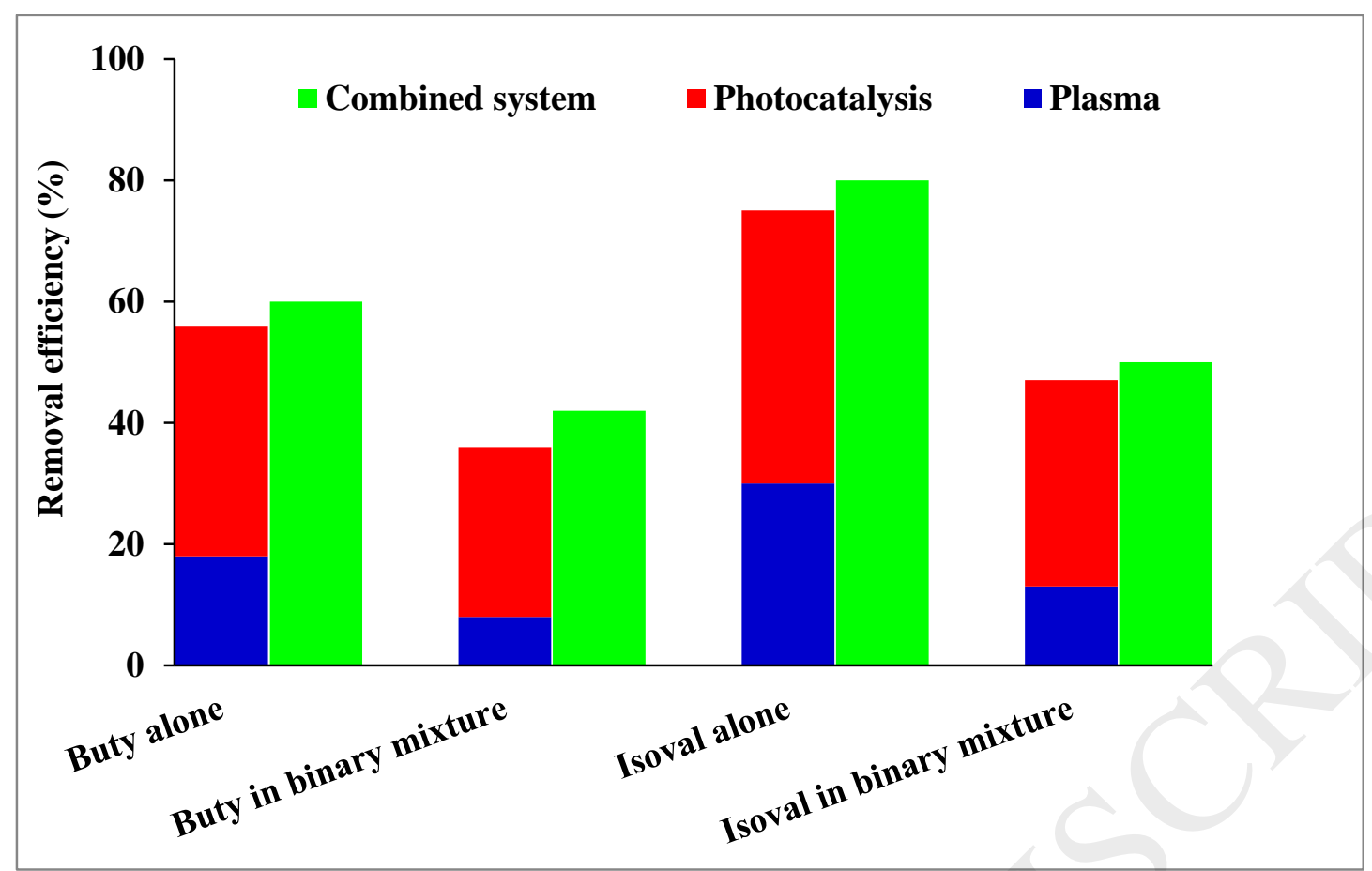

Figure 5: Removal efficiencies of Isoval and Buty in mono and multicomponent systems using NPSD plasma, photocatalysis and a combined process $\left(\mathrm{SDE}=14 \mathrm{~J} \mathrm{~L}^{-1}, \mathrm{UV}\right.$ intensity $\left.=20 \mathrm{Wm}^{-2}\right)$.

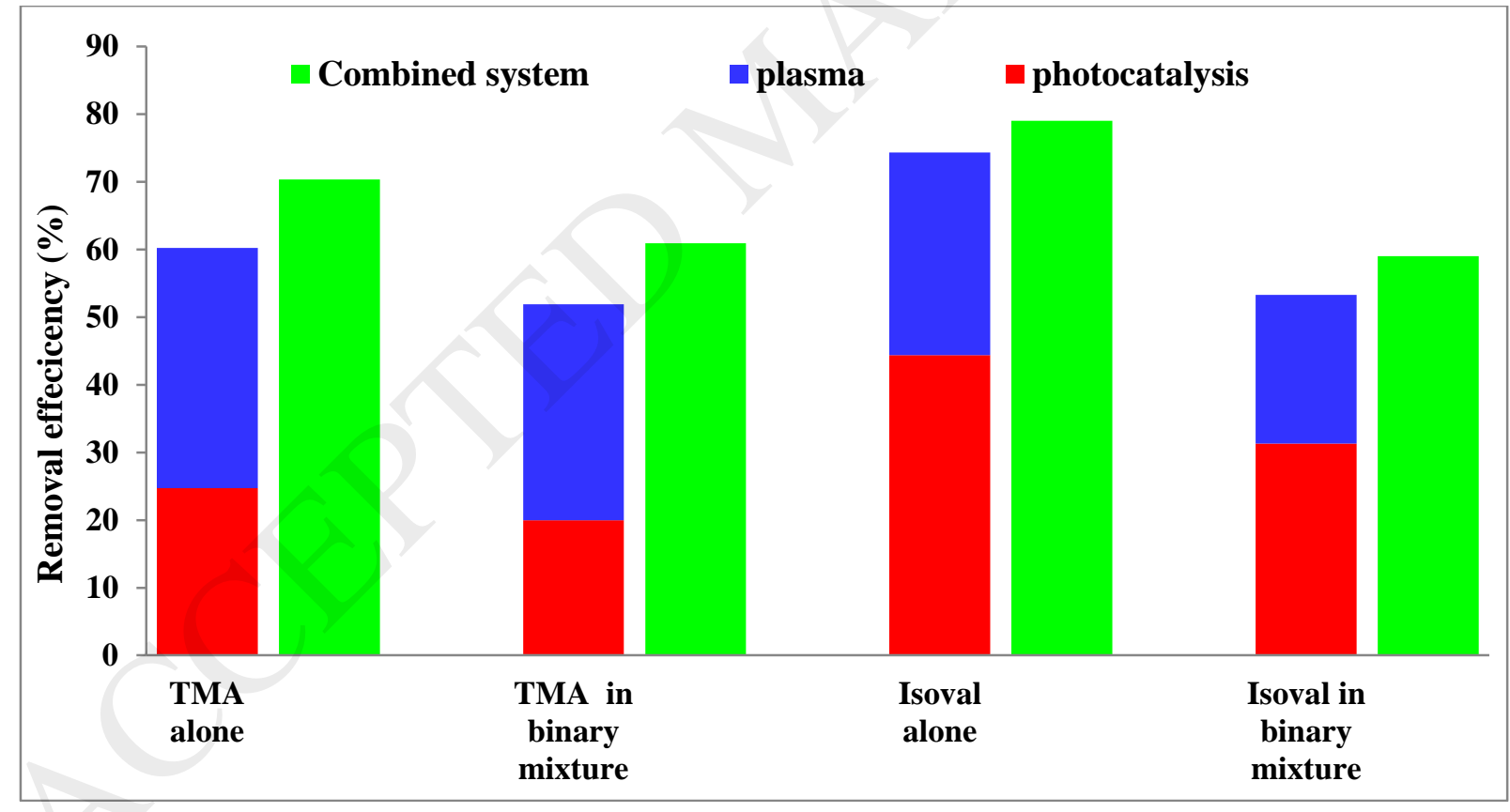

Figure 6: Removal efficiencies of Isoval and TMA in mono and multicomponent systems using plasma NPSD, photocatalysis and a combined processes $\left(\mathrm{SDE}=14 \mathrm{~J} \mathrm{~L}^{-1}, \mathrm{UV}\right.$ intensity $\left.=20 \mathrm{Wm}^{-2}\right)$. 


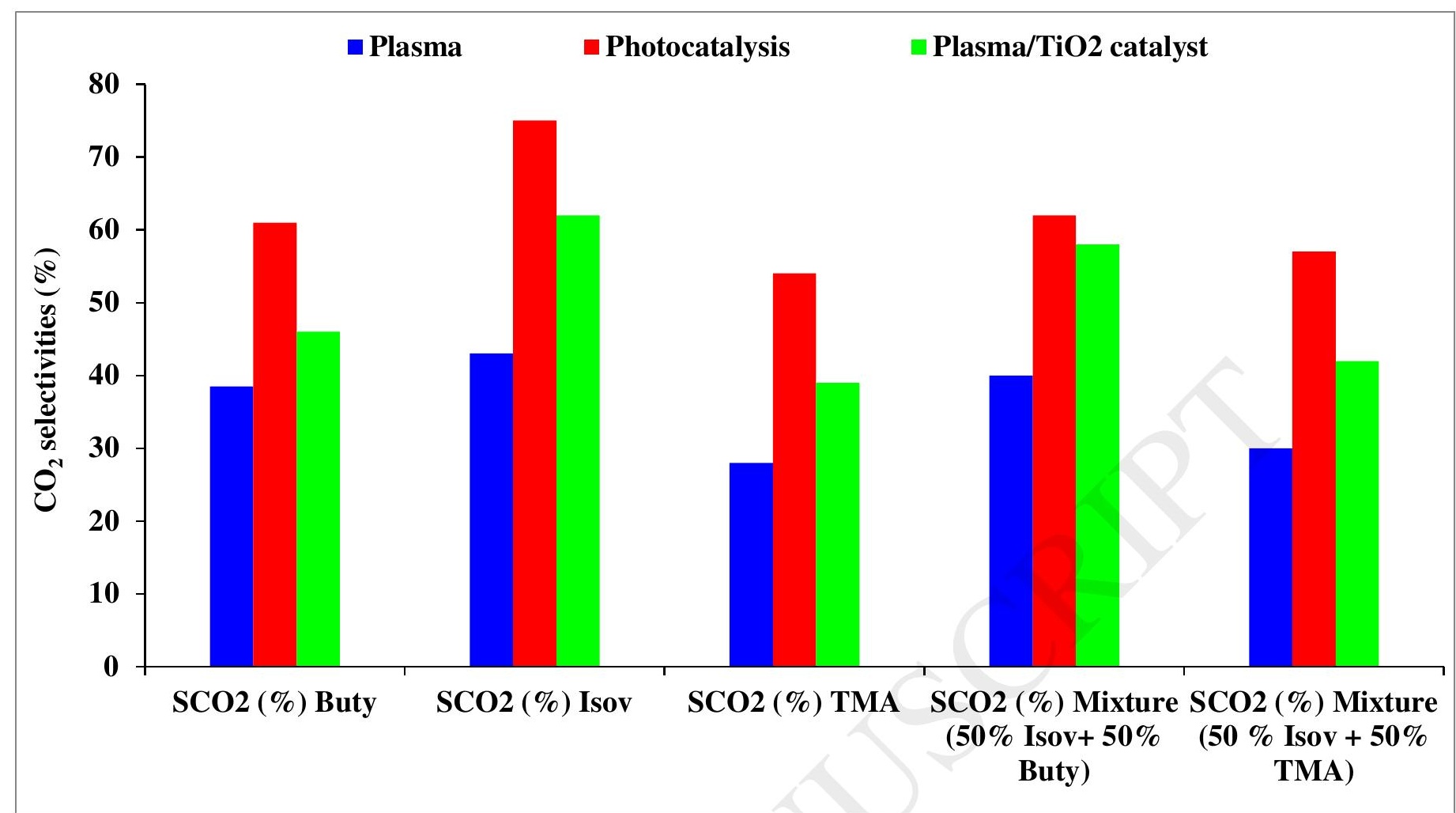

Figure 7: CO2 selectivity (\%) of three pollutants in single component and multicomponent systems using NPSD, photocatalysis and a combined process $\left(\mathrm{SDE}=14 \mathrm{~J} \mathrm{~L}^{-1}, \mathrm{UV}\right.$ intensity $\left.=20 \mathrm{Wm}^{-2}\right)$.

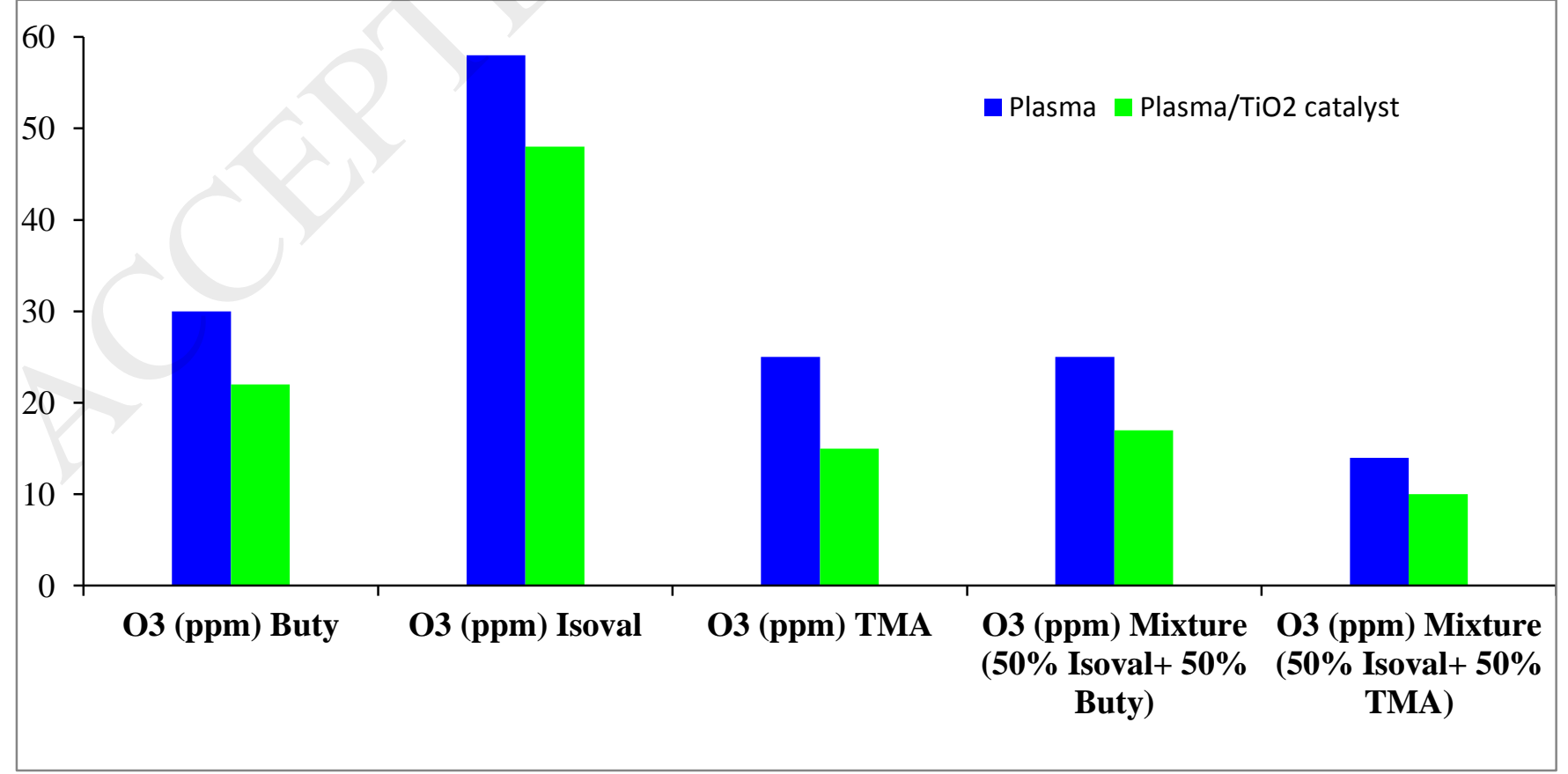


Figure 8: Ozone concentration produced (ppm) during the degradation of three pollutants in mono and multicomponent systems (50\% Isoval+50\% Buty \& 50\% Isoval+ 50\% TMA) using NPSD, and a plasma/TiO 2 reactor $\left(\mathrm{SDE}_{2}=14 \mathrm{~J} \mathrm{~L}^{-1}\right.$, UV intensity $\left.=20 \mathrm{Wm}^{-2}\right)$.

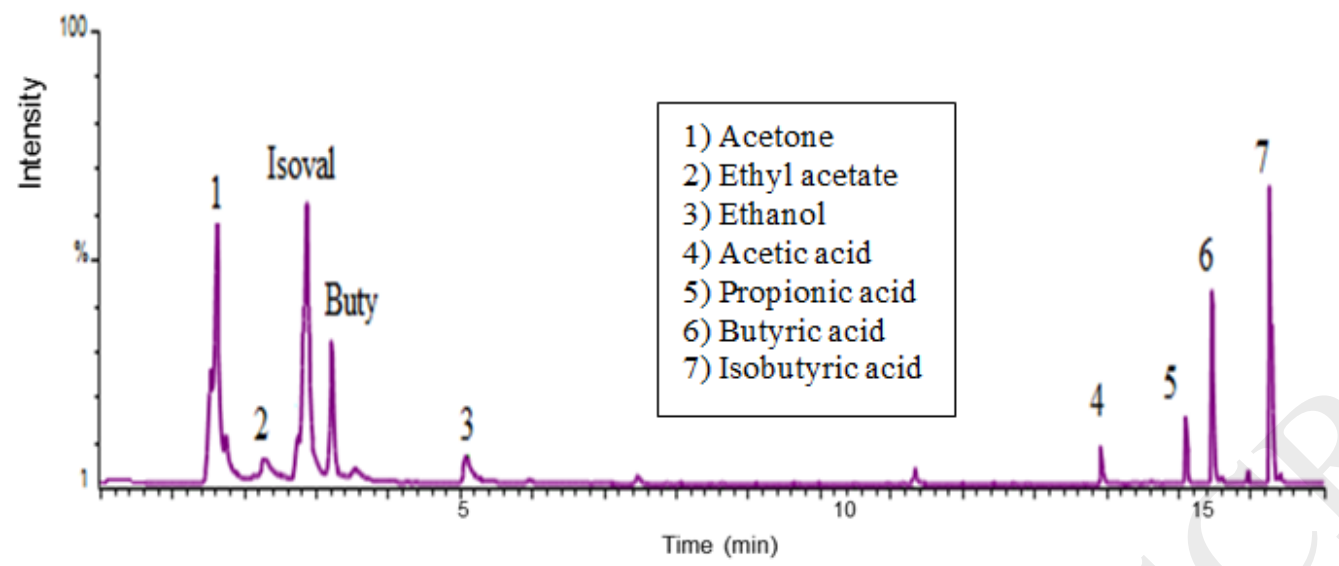

Figure 9: By-products identified during the oxidation of a mixture of $50 \%$ Buty and $50 \%$ Isoval in the combined system.

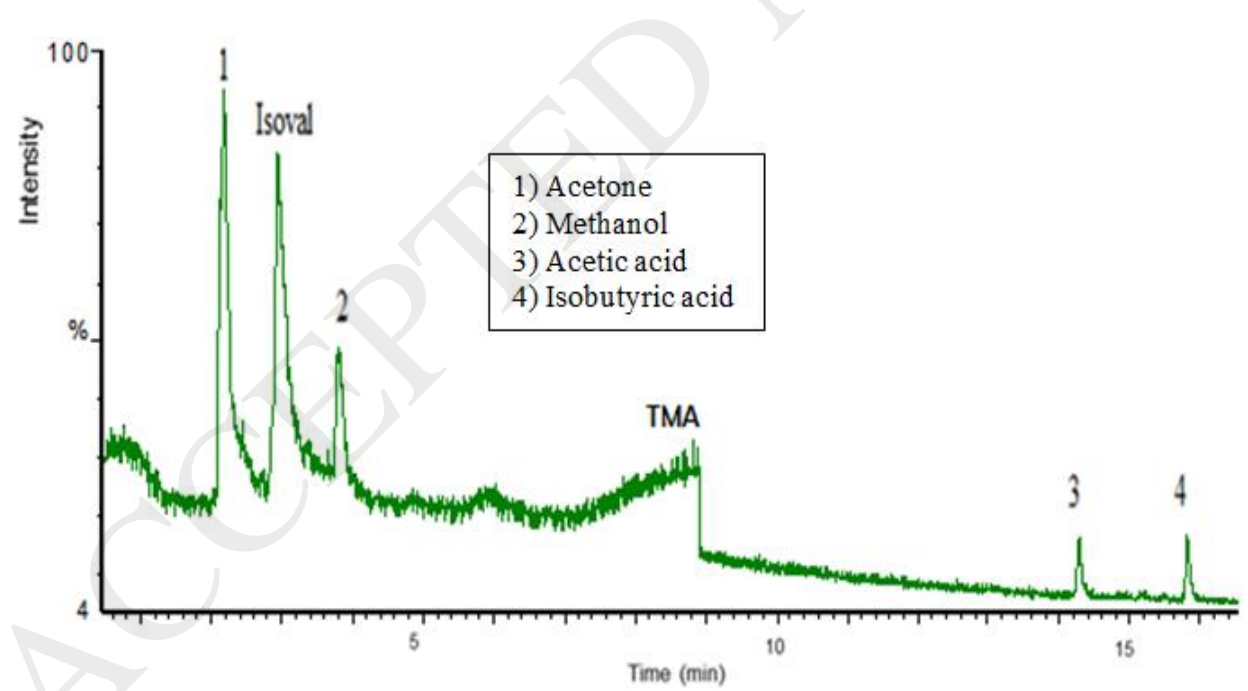

Figure 10: By-products generated during the oxidation of a mixture of $50 \%$ TMA and $50 \%$ Isoval, using in the combined system. 